\title{
Mutations of mtDNA polymerase- $\gamma$ and hyperlactataemia in the HIV-infected Zulu population of South Africa
}

\author{
D B A Ojwach, ${ }^{1,2}$ BSc Hons, MMedSci; C Aldous, ${ }^{2}$ PhD; P Kocheleff, ${ }^{3}$ MB ChB; B Sartorius, ${ }^{4}$ BSc, BSc Hons, MSc, EPIET, PhD \\ ${ }^{1}$ Discipline of Genetics and Microbiology, School of Life Sciences, College of Agriculture, Engineering and Science, University of KwaZulu-Natal, \\ Pietermaritzburg, South Africa \\ ${ }^{2}$ Discipline of Clinical Genetics, School of Clinical Medicine, College of Health Sciences, Nelson R Mandela School of Medicine, University of \\ KwaZulu-Natal, Durban, South Africa \\ ${ }^{3}$ Health Systems Trust, Pietermaritzburg, South Africa \\ ${ }^{4}$ Discipline of Public Health Medicine, School of Nursing and Public Health, College of Health Sciences, Nelson R Mandela School of Medicine, \\ University of KwaZulu-Natal, Durban, South Africa
}

Corresponding author: D B A Ojwach (dtyachieng@hotmail.com)

Background. Mitochondrial toxicity, particularly symptomatic hyperlactataemia or lactic acidosis (SHL/LA), has been attributed to the use of nucleoside reverse transcriptase inhibitors (NRTIs), possibly because of their capacity to impede human mitochondrial DNA polymerase- $\gamma$ (POLG), which is responsible for the replication of mitochondrial DNA.

Objective. To determine whether known monogenic POLG1 polymorphisms could be linked with the unexpectedly high incidence of SHL/ LA observed in HIV-infected Zulu-speaking patients exposed to the NRTIs stavudine or zidovudine in their antiretroviral therapy.

Methods. One hundred and sixteen patients from Edendale Hospital, Pietermaritzburg, South Africa, participated in the study between March and August 2014. Fifty-nine symptomatic cases were compared with 57 non-symptomatic controls on stavudine for $\geq 24$ months. Among the symptomatic patients, 13 had SHL with measured lactate between 3.0 and $4.99 \mathrm{mmol} / \mathrm{L}$, and 46 had LA with a lactate level $\geq 5 \mathrm{mmol} / \mathrm{L}$. Genomic DNA from 113 samples was used for subsequent allelic discrimination polymerase chain reaction screening for the R964C and E1143G single-nucleotide polymorphisms of POLG1. Sequencing was performed for 40/113 randomly selected samples for confirmation of the genotyping results.

Results. Neither of the two known POLG1 mutations was observed. The cases presented with SHL/LA between 4 and 18 months on stavudine. Females $(70.4 \%)$ were significantly $(p<0.001)$ more likely to be cases (adjusted odds ratio $24.24,95 \%$ CI 5.14 - 114.25) compared with males.

Conclusion. This study has shown that our sample of the Zulu-speaking population does not exhibit a genetic predisposition to SHL/LA associated with known monogenic POLG1 mutations, indicating another possible predisposing factor for increased risk of SHL/LA.

S Afr Med J 2016;106(12):1254-1259. DOI:10.7196/SAMJ.2016.v106i12.10818

Highly active antiretroviral therapy (HAART) has restricted HIVlinked mortality and morbidity. ${ }^{[1]}$ Unfortunately, in some patients HAART has been associated with adverse drug toxicity such as symptomatic hyperlactataemia (SHL) or lactic acidosis (LA). SHL and LA are related to the use of nucleoside reverse transcriptase inhibitors (NRTIs), occurring most frequently with zalcitabine, stavudine $(\mathrm{d} 4 \mathrm{~T})$, didanosine, zidovudine (AZT), and lamivudine and least frequently with abacavir/tenofovir. ${ }^{[2]}$ These NRTI sideeffects are implicated in mitochondrial toxicity, possibly because of their capacity to impede human mitochondrial DNA (mtDNA) polymerase- $\gamma$, which is responsible for the replication of the 16,569 bp mitochondrial genome. ${ }^{[3]}$ The $140 \mathrm{kDa}$ catalytic protein is translated from the 22 exons of the POLG1 gene on chromosome $15 \mathrm{q} 25$, and possesses both polymerase and $3^{\prime}-5^{\prime}$ exonuclease activities. ${ }^{[4]}$ Primary mutations in the POLG1 gene lead to secondary defects in the maintenance of the mitochondrial genome, depletion of mtDNA, ${ }^{[5,6]}$ damage to oxidative phosphorylation ${ }^{[6]}$ and elevation of serum lactate,,$^{[5,7]}$ thus making the POLG1 gene a strong candidate for NRTI-induced mitochondrial-toxicity-related disorders such as hyperlactataemia. Literature reports from developed countries suggest an incidence rate for SHL of 5 - 10/1 000 patients per year on NRTIs and 1/1 000 patients per year for the very severe form (LA), which is associated with a high expected mortality. ${ }^{[8]}$

In South Africa (SA), SHL/LA incidence appears notably high, ${ }^{[9-15]}$ especially in KwaZulu-Natal (KZN) Province, which is predominantly inhabited by the SA Zulu-speaking population. ${ }^{[10,12,14]}$ The objective of this study was to detect if known mutations in mtDNA polymerase- $\gamma$ $(P O L G 1)^{[16,17]}$ reported to be associated with mitochondrial toxicity are also linked with NRTI-induced SHL/LA in the SA Zulu-speaking population.

\section{Methods}

Sample and clinical data collection

This case-control study comprised 116 HIV-infected adult (aged 18 50 years) patients already enrolled on antiretroviral (ARV) treatment according to the National ARV Treatment Guidelines (2004) of the National Department of Health $(\mathrm{NDoH})$ of SA. Patients on ARV treatment who experienced SHL/LA were classified as cases, and those patients on treatment with stavudine for $\geq 24$ months as part of their HAART regimen who did not experience SHL/LA were classed as controls. Patients were enrolled on the study on their scheduled routine clinical visit at Edendale Hospital, a regional-level public sector institution in Pietermaritzburg, SA, between March and August 2014.

For evaluation of the cases enrolled in this study, patients were reviewed based on definition of their lactate levels as follows:

- Normal: Documented lactate levels $<2 \mathrm{mmol} / \mathrm{L}$

- SHL: Documented lactate levels $>4.0 \mathrm{mmol} / \mathrm{L}$ but $<5.0 \mathrm{mmol} / \mathrm{L}$, accompanied by symptoms

- Severe SHL: Documented lactate levels $>5.0 \mathrm{mmol} / \mathrm{L}$ with severe symptoms, and in patients recorded as having decreasing $\mathrm{pH}$ 
- Lactic acidosis: Patients with a decreasing $\mathrm{pH}<7.35$ and decreasing bicarbonate $<17 \mathrm{mmol} / \mathrm{L}$ caused by SHL. ${ }^{[18]}$

Key baseline and longitudinal data were collected (Table 1) including the selected independent variables of age, gender, ethnicity, weight, height, body mass index (BMI) and duration of treatment with stavudine- or zidovudine-containing regimens. The dependent variables were a lactate level $>4 \mathrm{mmol} / \mathrm{L}$ and acid base status (bicarbonate $<17 \mathrm{mmol} / \mathrm{L}$ ).

\section{DNA extraction}

Genomic DNA was isolated from 113 of the 116 patients' blood samples using the QIAmp DNA Blood Mini Kit (Qiagen, Germany) according to the manufacturer's instructions. The purity and quantity were assessed using a Nano Drop ND-1000 spectrophotometer (Rockland, USA). R964C and E1143G POLG1 single-nucleotide polymorphisms (SNPs) were determined by allelic discrimination real-time polymerase chain reaction (PCR) after a series of numerous optimisation reactions using primers and probes (Table 2).

\section{Allelic discrimination PCR}

The amplification of both SNPs was performed in duplicate using 5 - $20 \mathrm{ng} / \mu \mathrm{L}$ of $3 \mu \mathrm{L}$ genomic DNA in $25 \mu \mathrm{L}$ reaction volume comprising $10 \mu \mathrm{L}$ of 1XTaqman genotyping PCR Master Mix: $3 \mu \mathrm{L}$ of both POLG1 primers $(1 \mu \mathrm{M}), 2 \mu \mathrm{L}$ of each probe $(0.5 \mu \mathrm{M})$ and $2 \mu \mathrm{L}$ of $\mathrm{ddH}_{2} \mathrm{O}$ (Qiagen, Germany) for E1143G, and $1 \mu \mathrm{L}$ of each probe $(0.25 \mu \mathrm{M})$ and $4 \mu \mathrm{L}$ of $\mathrm{dd}_{2} \mathrm{O}$ (Qiagen, Germany) for R964C. The PCR amplification and detection, performed on a 7500 Realtime PCR Applied Biosystems machine (Applied Biosystems, USA), entailed initial denaturation at $95^{\circ} \mathrm{C}$ for 10 minutes, followed by
40 cycles of denaturation at $92^{\circ} \mathrm{C}$ for 15 seconds and annealing at $60^{\circ} \mathrm{C}$ for 60 seconds. This was also confirmed by resolving on $2 \%$ (w/v) agarose gel (Figs 1 and 2).

\section{Nucleotide sequencing}

DNA sequencing was performed on 40 randomly selected samples to cross-check the accuracy of the genotyping results. The same forward and reverse primers (previously used for allelic discrimination realtime amplification of the R964C and E1143G polymorphisms) were used (Table 2). A $50 \mu \mathrm{L}$ reaction volume was used containing $10 \mu \mathrm{L}$ of genomic DNA $(5-20 \mathrm{ng} / \mu \mathrm{L}), 5 \mu \mathrm{L}$ of $5 \mathrm{X}$ Supertherm reaction buffer, $3 \mu \mathrm{L} \mathrm{MgCl}_{2}(25 \mathrm{mM}), 4 \mu \mathrm{L}$ dNTPs $(2.5 \mu \mathrm{M}), 4 \mu \mathrm{L}$ of each primer $(1 \mu \mathrm{M}), 0.3 \mu \mathrm{L}$ of SuperthermTaq DNA polymerase (250 U/ $\mu \mathrm{L}$ ) and $19.7 \mu \mathrm{L}$ of $\mathrm{ddH}_{2} 0$ (Qiagen, Germany). The PCR products were purified using glass fibre filters (Roche High PCR Product Purification Kit, Germany) according to manufacturer's protocol and sequenced in forward and reverse orientations. Finally, the reaction products were reconstituted with $15 \mu \mathrm{L}$ of $\mathrm{Hi}$-Di formamide (Applied Biosystems, USA) and run on the ABI PRISM 310 Genetic Analyzer (Applied Biosystems, USA). Alignments of the sequences were performed using Genescan Software v3.1.0. (Applied Biosystems, USA).

\section{Data analysis}

Data were analysed using Stata 13.0 (StataCorp, USA). Gene-wise comparisons of R964C and E1143G allele frequencies between the case and control groups for each SNP and individual allelic association tests for an SNP were assessed using Pearson's $\chi^{2}$ test or Fisher's exact test. Similarly bivariate (unadjusted) comparisons of other categorical independent variables by case/control status were

Table 1. Demographic and clinical data of patients enrolled in the study

\begin{tabular}{|c|c|c|c|}
\hline Characteristics & Cases $(n=59)$ & Controls $(n=57)$ & $p$-value ${ }^{*}$ \\
\hline \multicolumn{4}{|l|}{ Demographics } \\
\hline Age (years), median (IQR) & $38(33-45)$ & $33(28-40)$ & 0.0151 \\
\hline Male, $n(\%)$ & $2(3.4)$ & $33(57.9)$ & $<0.001$ \\
\hline Female, $n(\%)$ & $57(96.6)$ & $24(42.1)$ & \\
\hline Black ethnicity (Zulu), $n /$ total (\%) & $59 / 59(100.0)$ & $57 / 57(100.0)$ & NC \\
\hline \multicolumn{4}{|l|}{ Baseline measurements } \\
\hline Weight baseline $(\mathrm{kg})$, median (IQR) & $71.4(58-83)$ & $58(53-68)$ & 0.0001 \\
\hline \multicolumn{4}{|l|}{ Weight $(\mathrm{kg}), n /$ total $(\%)$} \\
\hline$<55$ & $10 / 57(17.5)$ & $18 / 53(34)$ & $<0.001$ \\
\hline $55-<60$ & $7 / 57(12.3)$ & $10 / 53(18.9)$ & \\
\hline $60-<65$ & $5 / 57(8.8)$ & $7 / 53(13.2)$ & \\
\hline $65-<70$ & $4 / 57(7.0)$ & $9 / 53(17.0)$ & \\
\hline $70-<75$ & $8 / 57(14.0)$ & $6 / 53(11.3)$ & \\
\hline$\geq 75$ & $23 / 57(40.4)$ & $3 / 53(5.7)$ & \\
\hline BMI $\left(\mathrm{kg} / \mathrm{m}^{2}\right)$ baseline, median (IQR) & $29(24.6-32.9)$ & $20.7(19.5-26.3)$ & 0.0017 \\
\hline \multicolumn{4}{|l|}{ BMI category, $n /$ total $(\%)$} \\
\hline Underweight $\left(10-18.5 \mathrm{~kg} / \mathrm{m}^{2}\right)$ & $1 / 25(4.0)$ & $2 / 16(12.5)$ & 0.0890 \\
\hline Healthy $\left(18.6-25 \mathrm{~kg} / \mathrm{m}^{2}\right)$ & $7 / 25(28.0)$ & $9 / 16(56.3)$ & \\
\hline Overweight $\left(25.1-30 \mathrm{~kg} / \mathrm{m}^{2}\right)$ & $7 / 25(28.0)$ & $4 / 16(25.0)$ & \\
\hline Obese $\left(30.1-40 \mathrm{~kg} / \mathrm{m}^{2}\right)$ & $9 / 25(36.0)$ & $1 / 16(6.3)$ & \\
\hline Very obese $\left(40.1-70 \mathrm{~kg} / \mathrm{m}^{2}\right)$ & $1 / 25(4)$ & $0 / 16(0)$ & \\
\hline \multicolumn{4}{|l|}{ Baseline laboratory results } \\
\hline CD4+ T-cell count baseline cells/ $\mu \mathrm{L}$, median (IQR) & $121(56-156)$ & $89(26-170)$ & 0.3388 \\
\hline Duration on stavudine months, median (IQR) & $11(8.0-14.0)$ & $68(49.0-79.5)$ & $<0.001$ \\
\hline
\end{tabular}


Table 2. Primers and probes used for allelic discrimination real-time PCR of the R964C and E1143G polymorphisms of POLG

\begin{tabular}{|c|c|c|c|c|}
\hline SNP & & Sequence & & PCR product size \\
\hline \multirow[t]{4}{*}{$\mathrm{C}-2890 \mathrm{~T}$} & Forward & Primer & 5'-GCCAAAATCTTCAACTACG-3' & \\
\hline & Reverse & & 5'-TGGGTGTTAAAGTGGATG-3' & 180 \\
\hline & Sense-wild & Probe & CAGCCСTTTGCTGAGCGCTTACTAAT & \\
\hline & Sense-mutant & & CAGCCCTTTGCTGAGTGCTTACTAAT & \\
\hline \multirow[t]{4}{*}{ A-3428G } & Forward & Primer & 5'-TGGCTGTTTGAAGAGTTTG-3' & \\
\hline & Reverse & & $5^{\prime}$-CGCATACCTGGTCAAGAG-3' & 138 \\
\hline & Antisense-wild & Probe & CGGTCCTCCTCCCGCACCAG & \\
\hline & Antisense-mutant & & CGGTCCTCCСCCCGCACCAG & \\
\hline
\end{tabular}

Table 3. Risk factors associated with SHL/LA confirmed by this study ${ }^{\star}$

\begin{tabular}{|c|c|c|c|c|}
\hline \multirow[b]{2}{*}{ Variable } & \multicolumn{2}{|c|}{ Bivariate } & \multicolumn{2}{|c|}{ Multivariable adjusted } \\
\hline & OR $(95 \%$ CI $)$ & $p$-value & OR $(95 \%$ CI $)$ & $p$-value \\
\hline Age & $1.04(1.00-1.08)$ & 0.078 & $1.03(0.98-1.09)$ & 0.184 \\
\hline Female & $39.19(8.70-176.48)$ & $<0.001^{\dagger}$ & $24.24(5.14-114.25)$ & $<0.001^{\dagger}$ \\
\hline Weight (kg) & $1.06(1.03-1.10)$ & $<0.001^{+}$ & $1.04(1.00-1.09)$ & 0.035 \\
\hline $55-<60$ & $1.26(0.37-4.34)$ & 0.714 & & \\
\hline $60-<65$ & $1.29(0.32-5.13)$ & 0.722 & & \\
\hline $65-<70$ & $0.80(0.20-3.27)$ & 0.756 & & \\
\hline $70-<75$ & $2.4(0.65-8.90)$ & 0.19 & & \\
\hline$\geq 75$ & $13.8(3.3-57.67)$ & $<0.001^{+}$ & & \\
\hline CD4+ 107/116 (92\%) & $1(1.00-1.01)$ & 0.447 & $1(0.99-1.00)$ & 0.421 \\
\hline Duration on stavudine (months) & $0.57(0.35-0.93)$ & 0.025 & & \\
\hline Viral load 19/116 (16\%) & $1(1.00-1.00)$ & 0.46 & & \\
\hline
\end{tabular}

performed using Pearson's $\chi^{2}$ test or Fisher's exact test. Bivariate comparisons of medians of continuous independent variables by case/control status were performed using Wilcoxon's rank-sum test. Finally, a multivariable adjusted logistic regression model was also developed to assess variables associated with case/control status to adjust for confounding and to estimate adjusted odds ratios (AORs). A $p$-value of $<0.05$ was considered to indicate possible statistical significance.

\section{Results}

\section{Clinical data}

The cases were diagnosed with hyperlactataemia between 4 and 18 months on ART, with a median of 11 months (interquartile range (IQR) 8 - 14 months). All the cases $(n=59)$ were on stavudine at the time of SHL/LA diagnosis. At the point of enrolment to the study, 42 of the 59 cases $(71.2 \%)$ were on zidovudine, compared with one patient out of $57(1.8 \%)$ in the control group. None of the 116 patients had SHL/LA symptoms or relapse at the time of enrolment in the study.

Females comprised the majority of cases at $96.6 \%$, compared with $42.1 \%$ in the control group (AOR 24.24, 95\% CI 5.14 - 114.25).The baseline age of the cases and controls when they initiated ART was significantly different $(p=0.0151)$ between the two groups. Median CD4 count at baseline was 121 cells/ $\mu \mathrm{L}$ (IQR 56 - 156) for the cases compared with 89 cells/ $\mu \mathrm{L}$ (IQR 26 - 170) for the controls. The median CD4 T-cell count at the time of hyperlactataemia diagnosis for the cases was 206 (IQR 32 - 538). Other characteristics are presented in Table 1.

Sixty-two percent of the cases (37/59) had lactate values between $5 \mathrm{mmol} / \mathrm{L}$ and $10 \mathrm{mmol} / \mathrm{L}$ and $15 \%(9 / 59)$ had documented lactate of $>10 \mathrm{mmol} / \mathrm{L}$. The median bicarbonate level was $19.5 \mathrm{mmol} / \mathrm{L}$ (IQR 17 - 22). It took a median time of 4 months for lactate levels to normalise after a median duration of 2 months' drug holiday (time off ARV medication). The most common symptoms were weight loss, recorded for $98.3 \%$ of the cases, loss of appetite $(84.7 \%)$ and peripheral neuropathy (56.0\%) (data not shown). Eighty-five percent of the cases had virological suppression at the time of diagnosis, with their viral load $<400$ copies $/ \mathrm{mL}$.

Where both weight and height measurements were available (23 cases and 18 controls), BMI $\left(\mathrm{kg} / \mathrm{m}^{2}\right)$ was calculated. Only $6.3 \%$ of the controls had a BMI of $\geq 30$ (obese) compared with $36.0 \%$ of cases (Table 1). On bivariate and multivariate analysis, female gender 
(AOR 24.24, 95\% CI $5.14-114.25, p<0.001$ ) and high initiating body weight (OR 13.80, 95\% CI $3.30-57.67, p=0.001$ ) remained significantly associated with SHL/LA (Table 3 ).

\section{Allelic discrimination PCR and sequencing}

According to the allelic discrimination real-time PCR amplification assay employed for screening of the polymorphisms, out of the 113 samples of sufficient yield and purity, none appeared to have either the variant allele $\mathrm{T}$ for the $\mathrm{R} 964 \mathrm{C}$ or variant allele $\mathrm{G}$ for the E1143G monogenic polymorphisms, in their POLG1 gene. Subsequent confirmation of the genotypes with sequencing had similar outcomes (Table 4) and no inconsistencies were illustrated between the two analytical approaches (Figs 1 - 4).

No significant association between the R964C and E1143G polymorphisms with hyperlactataemia disease was established; neither the cases nor the controls had any R964C and E1143G variant alleles or the homozygous variant genotypes (Table 4 and Figs 3 - 4). These findings suggest that association of these known monogenic POLG1 mutations with SHL/LA in the Zulu-speaking SA population is not common.

\section{Discussion}

Of the 116 HIV-positive patients, concerns of intolerance to firstline therapy because of mitochondrial toxicity were significant for the 59 cases on stavudine therapy that were diagnosed with hyperlactataemia between 4 and 18 months, with a median range of 11 months. This period to diagnosis was consistent with larger cohorts in similar settings. ${ }^{[9,19,20]}$ All the cases $(n=59)$ were on stavudine therapy at the time of SHL/LA diagnosis and the controls ( $n=56)$ had been on stavudine for $\geq 24$ months. At the time of enrolment in the study, none of the cases was on stavudine compared with the controls (21/57). Eleven months of exposure to stavudine in the cases compared with 68 months in the controls $(p<0.001)$ clearly demonstrates that the use of stavudine poses a risk in the development of SHL/LA, as documented by other investigators. ${ }^{[8,9,11,12,14,21]}$ While a significant number of the cases (42/59) were on zidovudine treatment at the time of enrolment in the study, only one patient among the control group $(n=57)$ was on similar treatment. The 42 cases on zidovudine did not show any symptoms or relapse of SHL/LA,

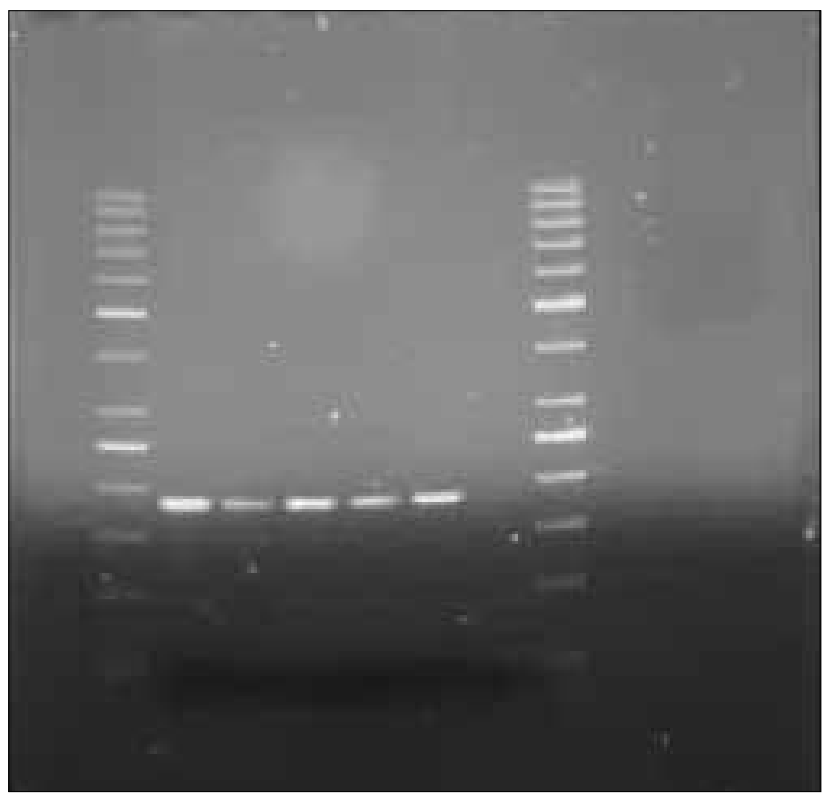

Fig. 1. Amplification of the R964C SNP in exon 18 of POLG resolved on a $2 \%(w / v)$ agarose gel.

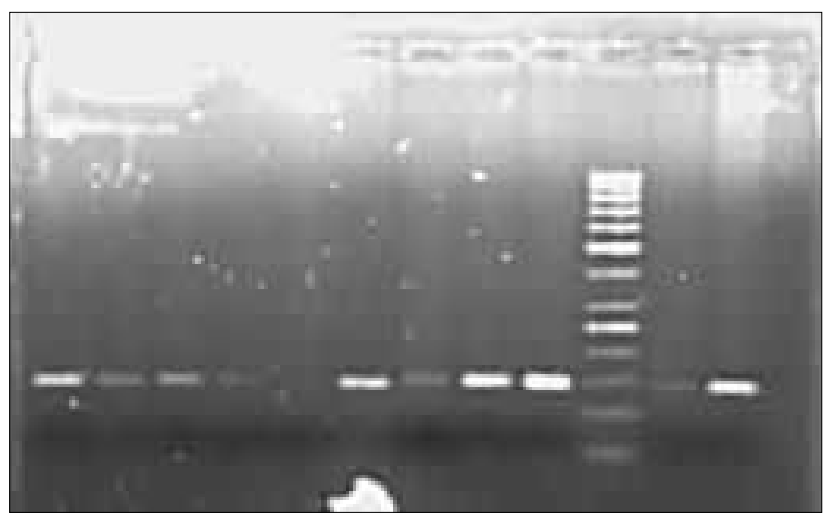

Fig. 2. Amplification of the E1143G SNP in exon 21 of POLG resolved on a $2 \%(w / v)$ agarose gel with molecular size marker.

\begin{tabular}{llll}
\multicolumn{1}{l}{ Table 4. Allele and genotype frequencies for the R964C and E1143G polymorphisms } & Controls, $\boldsymbol{n}$ (\%) \\
\hline Genotype & POL $1 \%)$ & Cases & \\
Homozygous wild-type & R964C & $56(100)$ & 0 \\
Heterozygous & CC & 0 & 0 \\
Homozygous variant & CT & 0 & 57 \\
Total & TT & 56 & $57(100)$ \\
Genotype & E1143G & & 0 \\
Homozygous wild-type & AA & $56(100)$ & 0 \\
Heterozygous & AG & 0 & $57(100)$ \\
Homozygous variant & GG & 0 & 0 \\
Allele frequencies & & & $57(100)$ \\
Wild-type R964C & C allele & $56(100)$ & 0 \\
Variant & T allele & 0 &
\end{tabular}




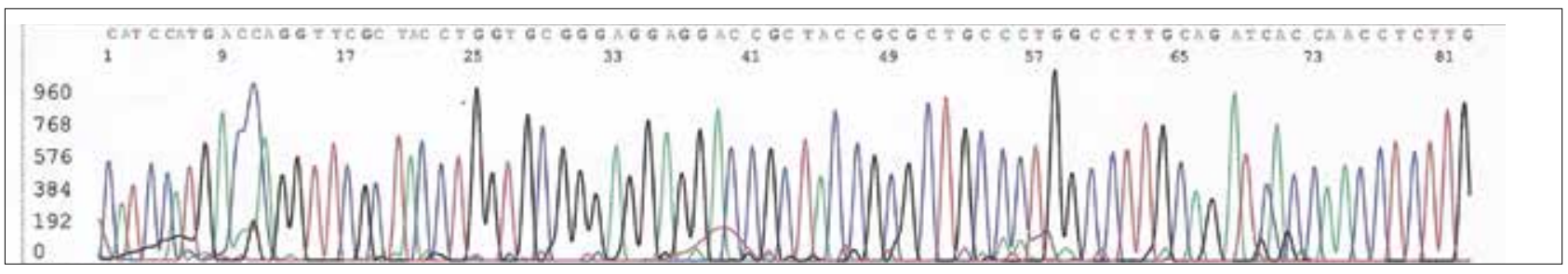

Fig. 3. Electropherogram plot of sequencing analysis of sample 26 forward primer of E1143G SNP of POLG.

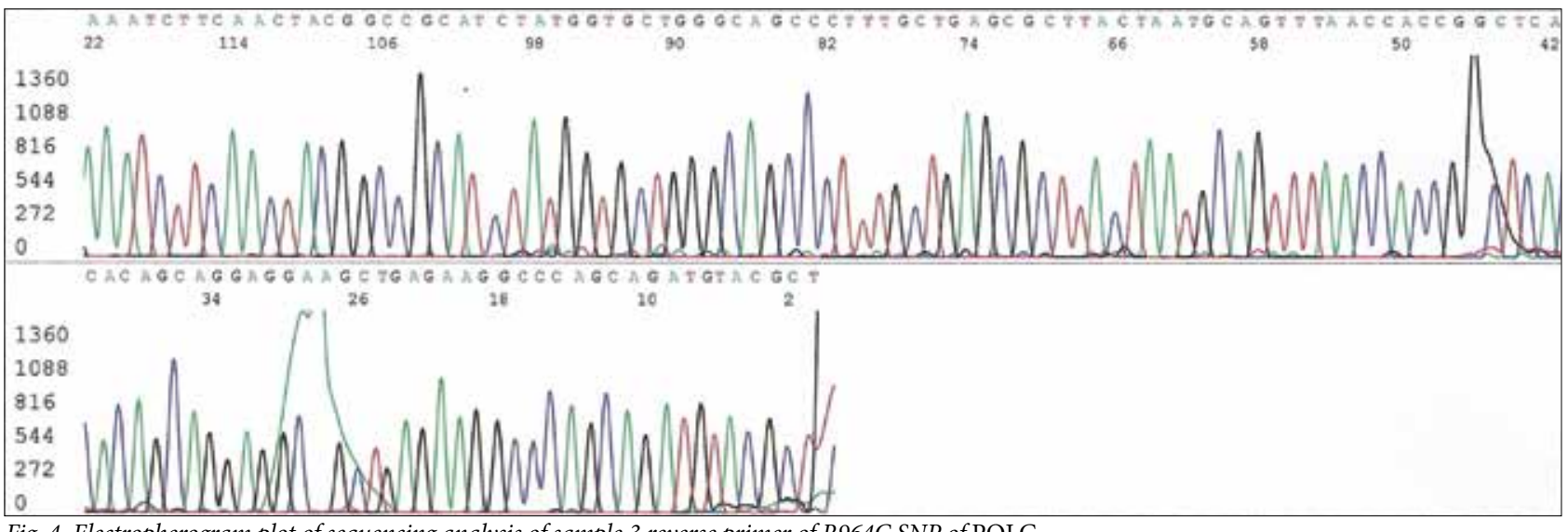

Fig. 4. Electropherogram plot of sequencing analysis of sample 3 reverse primer of R964C SNP of POLG.

indicating that changing from stavudine to zidovudine is linked with decreased risk of SHL/LA relapse. ${ }^{[22,23]}$ This strategy has been clearly documented in other studies. ${ }^{[9,19]}$

Female gender, age, high initiating body weight and treatment with stavudine were significantly associated with increased risk of SHL/LA. These risk factors are consistent with those reported by other studies in related settings, ${ }^{[10,12,14]}$ as well as in other studies globally. ${ }^{[8,15,24-26]}$ In this study, the baseline age of the cases and controls was significantly different $(p=0.015)$, with a median age of 38 (IQR 33 - 45) and 33 (IQR 28 - 40) years for cases and controls, respectively. This is in good agreement with studies that have shown associations between SHL/ LA and advanced age. ${ }^{[24,25]}$ Other studies have reported low baseline CD4 count ${ }^{[12,24,26]}$ as a factor associated with SHL/LA. In this study, the controls had a lower baseline CD4 count median, of 89 cells $/ \mu \mathrm{L}$ (IQR 26 - 170) compared with 121 cells/ $\mu \mathrm{L}$ (IQR 56 - 156) in cases, at the time of hyperlactataemia diagnosis. Hence it is conceivable from this study that there is no association between CD4 count and SHL/ LA among the SA population, in good agreement with the reports of Osler and others. ${ }^{[11,27]}$ However, our findings contradict the results obtained by some researchers, in which a strong association between patient age ${ }^{[25]}$ and CD4 count ${ }^{[2,26]}$ and SHL/LA was observed. Several POLG1 mutations have been studied, resulting in deletions or point mutations in mtDNA and decreased polymerase activity. Although there is a spectrum in the degree of insufficiency in polymerase activity, the most severe mutations lead to loss of $>99 \%$ of polymerase function and cell death due to insufficient cellular energy production. ${ }^{[28,29]}$

The pathogenicity of the p.E1143G change, caused by an A-to-G substitution at nucleotide position 3428 in exon 21 , has been widely scrutinised. ${ }^{[28,30,31]}$ The substitution is found at a high frequency in control populations $(2-3 \%)$, and has never been identified alone in any disease patients. ${ }^{[32]}$ E1143 is a highly conserved amino acid located adjacent to motif $\mathrm{C}$ of the polymerase domain, and biochemical investigations show a possible role in the modular expression of other POLG1 mutations in cis. ${ }^{[33]}$

The POLG1 R964C mutation has been definitively associated with hyperlactataemia in an HIV-positive Thai female patient undergoing HAART with stavudine. ${ }^{[16]}$ Biochemical analysis demonstrated an $86 \%$ reduction in activity of recombinant R964C POLG1 compared with that of wild-type POLG1. Cultures in stavudine patient-derived lymphoblastoid cell lines (LCLs) had significantly reduced mtDNA levels compared with the LCLs of wild-type POLG1. ${ }^{[16]}$ Further biochemical analysis of the R964C holoenzyme showed a $33 \%$ decrease in dTTP incorporation efficiency and a threefold decreased discrimination for d4TTP compared with the wild-type POLG1. ${ }^{[29]}$ Thus, the POLG1 R964C mutation may be a cause of SHL caused by NRTI-mitochondrial dysfunction.

The POLG1 mutations associated with NRTI-mitochondrial toxicity to date, R964C and E1143G ${ }^{[16,17]}$ were not seen in any of the HIV-positive Zulu-speaking patients we screened. A direct relationship between the R964C/E1143G mutation and SHL cannot be determined from this study. Previous work has shown that neither the R964C nor E1143G POLG1 mutations were present among 14 Malawian HIV-positive patients on stavudine HAART. ${ }^{[34]}$ Collectively, it can be stipulated that these variants are not common among the black African population. However, whether R964C/ E1143G is a true functional mutation cannot be determined from this study but is evident in previous studies ${ }^{[16,17]}$ conducted in other populations. We cannot exclude the possibility that screening a larger number of patients would have shown some cases of POLG1 mutation associated with NRTI mitochondrial toxicity and SHL. Further, we only tested for two of the $>20$ described POLG1 mutations, so we are unable to exclude the possibility that mutations other than those that we tested for are associated with SHL and could explain the high incidence of stavudine-induced SHL/LA in the Zulu-speaking population.

\section{Conclusions}

This study significantly confirms the use of stavudine, female gender, age and high initiating baseline weight (high BMI) as risk factors for the development of SHL/LA, specific for the Zulu ethnic group. Similar factors have been reported by other investigators in both local and international settings. ${ }^{[10,12,14,24]}$

The R964C and E1143G polymorphisms within POLG1 were not observed in this study population. The study confirms that 
R964C, E1143G or both polymorphisms do not have a link to an increased risk of developing SHL/LA in stavudine-treated HIVinfected Zulu-speaking patients. These findings are similar to the outcomes described by other investigators testing similar mutations in Malawi, on a black African population. ${ }^{[34]}$ Collectively, it can be stipulated that these variants are not common among the black population.

Ethical approval. All procedures performed in this study were in accordance with the ethical standards of the institutional and/or national research committee and with the 1964 Helsinki declaration and its later amendments or comparable ethical standards. Study approval was obtained from the University of KZN Biomedical Review Ethical Committee (ref. no. BE309/13) and KZN Department of Health (ref. no. HRKM343/13). A letter of support for approval of research was obtained from Edendale Hospital.

Patient consent. All the patients provided signed informed consent for this study.

Acknowledgements. We are grateful to patients from the Edendale adult ARV clinic for participating in this study, as well as Dr D Haines, Dr N Nxumalo, Dr E Singh, Dr Rajkoomar, Dr B Adeyemi, Dr P Nys, Dr D Wilson and Sister P Nkonzo for their assistance with blood collection.

Funding. DBAO obtained funding from the College of Health Sciences, University of KZN and CA had a research grant from KZN Research Institute for Tuberculosis and HIV.

1. Tressler R, Godfrey C. NRTI backbone in HIV Treatment: Will it remain relevant? Drugs 2012;72(16):2051-2062. http://dx.doi.org/10.2165/11640830-000000000-00000

2. Kakuda TN. Pharm++acology of nucleoside and nucleoside reverse transcriptase inhibitor-induced mitochondrial toxicity. Clin Ther 2000;22(6):685-708. http://dx.doi.org/10.1016/S0149-2918(00)90004-3 3. Clayton DA. Replication of animal mitochondrial-DNA. Cell 1982;28(4):693-705. http://dx.doi. org/10.1016/0092-8674(82)90049-6

4. Kaguni LS. DNA polymerase gamma, the mitochondrial replicase. Ann Rev Biochem 2004;73:293-320. http://dx.doi.org/10.1146/annurev.biochem.72.121801.161455

5. Kohler JJ, Lewis W. A brief overview of mechanisms of mitochondrial toxicity from NRTIs. Environ Mol Mutagen 2007;48(3-4):166-172. http://dx.doi.org/10.1002/em.20223

6. Detmer SA, Chan DC. Functions and dysfunctions of mitochondrial dynamics. Nat Rev Mol Cell Biol 2007;8(11):870-879. http://dx.doi.org/10.1038/nrm2275

7. Falkenberg M, Larsson NG, Gustafsson CM. DNA replication and transcription in mammalian mitochondria. Annu Rev Biochem 2007;76:679-699. http://dx.doi.org/10.1146/annurev biochem.76.060305.152028

8. Arenas-Pinto A, Grant AD, Edwards S, Weller IV. Lactic acidosis in HIV infected patients: A systematic review of published cases. Sex Transm Infect 2003;79(4):340-343. http://dx.doi.org/10.1136/sti.79.4.340 9. Bolhaar MG, Karstaedt AS. A high incidence of lactic acidosis and symptomatic hyperlactatemia in women receiving highly active antiretroviral therapy in Soweto, South Africa. Clin Infect Dis 2007;45(2):254-260. http://dx.doi.org/10.1086/518976

10. Geddes R, Knight S, Moosa MY, Reddi A, Uebel K, Sunpath H. A high incidence of nucleoside reverse transcriptase inhibitor (NRTI)-induced lactic acidosis in HIV-infected patients in a South African context. S Afr Med J 2006;96(8):722.

11. Stead D, Osler M, Boulle A, Rebe K, Meintjes G. Severe hyperlactataemia complicating stavudine first-line antiretroviral therapy in South Africa. Antivir Ther 2008;13(7):937-943. http://dx.doi. org/10144/41770
12. Hernandez Perez E, Dawood H. Stavudine-induced hyperlactatemia/lactic acidosis at a tertiary communicable diseases clinic in South Africa. J Int Assoc Physicians AIDS Care (Chic) 2010;9(2):109112. http://dx.doi.org/10.1177/1545109710361536

13. Dlamini J, Ledwaba L, Mokwena N. Short communication lactic acidosis and symptomatic hyperlactataemia in a randomized trial of first-line therapy in HIV-infected adults in South Africa. Antivir Ther 2011;16:605-609. http://dx.doi.org/10.3851/IMP1790

14. Leung L, Wilson D, Manini AF. Fatal toxicity from symptomatic hyperlactataemia: A retrospective cohort study of factors implicated with long-term nucleoside reverse transcriptase inhibitor use in a South African Hospital. Drug Saf 2011;34(6):521-527. http://dx.doi.org/10.2165/11588240-000000000-00000

15. Fabian J, Venter WD, Mkhabela L, Levin JB, Baker L, Naicker S. Symptomatic hyperlactataemia in adults on antiretroviral therapy: A single-centre experience. S Afr Med J 2008;98(10):795-800.

16. Yamanaka H, Gatanaga $\mathrm{H}$, Kosalaraksa P. Novel mutation of human DNA polymerase gamma associated with mitochondrial toxicity induced by anti-HIV treatment. J Infect Dis 2007;195(10):1419-1425. http:// dx.doi.org/10.1086/513872

17. Chiappini F, Teicher E, Saffroy R, Debuire B, Vittecoq D, Lemoine A. Relationship between polymerase gamma (POLG) polymorphisms and antiretroviral therapy-induced lipodystrophy in HIV-1 infected patients: A case-control study. Curr HIV Res 2009;7(2):244-253. http://dx.doi. org/10.2174/157016209787581409

18. Calza L, Manfredi R, Chiodo F. Hyperlactataemia and lactic acidosis in HIV-infected patients receiving antiretroviral therapy. Clin Nutr 2005;24(1):5-15. http://dx.doi.org/10.1016/j.clnu.2004.03.009

19. Matthews LT, Giddy J, Ghebremichael M, et al. A risk-factor guided approach to reducing lactic acidosis and hyperlactatemia in patients on antiretroviral therapy. PLoS One 2011;6(4):e18736. http://dx.doi. org/10.1371/journal.pone. 0018736

20. Ogedegbe AEO, Thomas DL, Diehl AM. Hyperlactataemia syndromes associated with HIV therapy. Lancet Infect Dis 2003;3(6):329-337. http://dx.doi.org/10.1016/S1473-3099(03)00654-6

21. Falcó V, Rodríguez D, Ribera E, et al. Severe nucleoside-associated lactic acidosis in human immunodeficiency virus-infected patients: Report of 12 cases and review of the literature. Clin Infect Dis 2002;34(6):838-846. http://dx.doi.org/10.1086/33904

22. Lonergan JT, McComsey GA, Fisher RL, et al. Lack of recurrence of hyperlactatemia in HIVinfected patients switched from stavudine to abacavir or zidovudine. I Acquir Immune Defic Syndr 2004;36(4):935-942. http://dx.doi.org/10.1097/00126334-200408010-00007

23. Lonergan JT, Barber RE, Mathews WC. Safety and efficacy of switching to alternative nucleoside analogues following symptomatic hyperlactatemia and lactic acidosis. AIDS 2003;17(17):2495-2499. http://dx.doi.org/10.1097/01.aids.0000088177.01779.50

24. Lactic Acidosis International Study Group. Risk factors for lactic acidosis and severe hyperlactataemia in HIV-1-infected adults exposed to antiretroviral therapy. AIDS 2007;21(18):2455-2464. http://dx.doi org/10.1097/QAD, .0b013e3282f08cdc.

25. Wester CW, Okezie OA, Thomas AM, et al. Higher-than-expected rates of lactic acidosis among highly active antiretroviral therapy-treated women in Botswana: Preliminary results from a large randomized clinical trial J Acquir Immune Defic Syndr 2007;46(3):318-322 http://dx.doi or $/$ /10.1097/ QAI.0b013e3181568e $3 \mathrm{f}$

26. Bonnet F, Bonarek M, Morlat P, et al. Risk factors for lactic acidosis in HIV-infected patients treated with nucleoside reverse-transcriptase inhibitors: A case-control study. Clin Infect Dis 2003;36(10):1324-1328. http://dx.doi.org/10.1086/374601

27. Osler M, Stead D, Rebe K, et al. Risk factors for and clinical characteristics of severe hyperlactataemia in patients receiving antiretroviral therapy: A case-control study. HIV Med 2010;11(2):121-129. http.// dx.doi.org/10.1111/j.1468-1293.2009.00754.X

28. Graziewicz MA, Longley MJ, Bienstock RJ, et al. Structure-function defects of human mitochondrial DNA polymerase in autosomal dominant progressive external ophthalmoplegia. Nat Struct Mol Biol 2004;11(8):770-776. http://dx.doi.org/10.1038/nsmb805

29. Bailey CM, Kasiviswanathan R, Copeland WC, et al. R964C mutation of DNA polymerase gamma imparts increased stavudine toxicity by decreasing nucleoside analog discrimination and impairing polymerase activity. Antimicrob Agents Chemother 2009;53(6):2610-2612. http://dx.doi.org/10.1128/ AAC.01659-08

30. Baruffini E, Lodi T. Construction and validation of a yeast model system for studying in vivo the susceptibility to nucleoside analogues of DNA polymerase gamma allelic variants. Mitochondrion 2010;10(2):183-187. http://dx.doi.org/10.1016/j.mito.2009.10.002

31. Graziewicz MA, Longley MJ, Copeland WC. DNA polymerase gamma in mitochondrial DNA replication and repair. Chem Rev 2006;106(2):383-405. http://dx.doi.org/10.1021/cr040463d

32. Chan SS, Copeland WC. DNA polymerase gamma and mitochondrial disease: Understanding the consequence of POLG mutations. Biochim Biophys Acta 2009;1787(5):312-319. http://dx.doi. org $/ 10.1016 /$ j.bbabio. 2008.10 .007

33. Chan SS, Longley MJ, Copeland WC. Modulation of the W748S mutation in DNA polymerase $\gamma$ by the E1143G polymorphismin mitochondrial disorders. Human Mol Genet 2006:15(23):3473-3483. http:// dx.doi.org $/ 10.1093 / \mathrm{hmg} / \mathrm{ddl} 424$

34. Van Oosterhout JJ, Gardner K, Mallewa J, et al. Severe toxicity and polymerase-gamma gene abnormalities in Malawian adults on stavudine-based antiretroviral therapy. Pharmacogenet Genomics 2013;23(11):624-626. http://dx.doi.org/10.1097/FPC.0b013e3283655053

Accepted 27 June 2016. 